\title{
Tuberculin reactivity after neonatal percutaneous BCG immunisation
}

\author{
L P Ormerod, C Palmer
}

\begin{abstract}
A total of 348 neonates of Asian ethnic origin were given percutaneous BCG vaccination using a multiple puncture head. Fifty five $(15 \cdot 8 \%)$ were tuberculin negative when tested 6-9 weeks after vaccination, a significantly higher proportion than after intradermal vaccination. The number of abscesses after vaccination was however significantly lower. (Arch Dis Child 1993; 69: 155)
\end{abstract}

Neonatal BCG vaccination is recommended for children of Afro-Asian ethnic origin ${ }^{1}$ and has been shown to have a significant protective effect. $^{2}$ Tuberculin reactivity after neonatal intradermal BCG vaccination has been shown in a high proportion ${ }^{3}$ and to be sustained at 4 years ${ }^{4}$ and for up to 12 years. ${ }^{5}$ BCG vaccination by the percutaneous technique has recently been approved as an acceptable alternative technique for neonates and infants. ${ }^{6} \mathrm{~A}$ six month cohort of newborn babies vaccinated by the percutaneous technique was tuberculin tested to compare their reactivity with that reported after intradermal vaccination.

\section{Methods}

A total of 390 newborns of Asian ethnic origin born between 1 January and 30 June 1992 inclusive were given percutaneous BCG vaccine (Evans Medical Ltd) by the paediatric senior house officers, using the 18 needle multiple puncture head (Bignell Ltd). Tuberculin reactivity (Tine test, Lederle) was measured between 6-9 weeks after vaccination, and any abscess reported. The study was approved by the local research ethics committee.

The negative test results (table) were equally distributed through the months of vaccination. Forty two babies were not tested: five parents refused, nine were unavailable for reading the test, in eight there was no access, and 20 moved out of the area or were on holiday. There was no difference statistically (by $\chi^{2}$ test) between any of the weeks 6-9. One baby born on 1 January 1992 had a small abscess that settled spontaneously;

Chest Clinic, Blackburn Royal Infirmary, Blackburn, Lancashire BB2 3LR L P Ormerod C Palmer

Correspondence to: Dr Ormerod.

Accepted 2 March 1993

\section{Results of tuberculin testing}

\begin{tabular}{lccc}
\hline $\begin{array}{l}\text { Age } \\
\text { (weeks) }\end{array}$ & $\begin{array}{l}\text { Total No } \\
\text { tested }\end{array}$ & $\begin{array}{l}\text { No tuberculin } \\
\text { positive }\end{array}$ & $\begin{array}{l}\text { No(\%) tuberculin } \\
\text { negative }\end{array}$ \\
\hline 6 & 31 & 25 & $6(19 \cdot 3)$ \\
7 & 127 & 108 & $19(15 \cdot 0)$ \\
8 & 104 & 84 & $20(19 \cdot 2)$ \\
9 & 86 & 76 & $10(11 \cdot 6)$ \\
Total & 348 & 293 & $55(15 \cdot 8)$ \\
\hline
\end{tabular}

$\star$ All positive tuberculin reactions were grade 1 . no other abscesses occurred. The abscess rate was $1 / 348(0 \cdot 29 \%)$.

A study of the tuberculin reactivity after neonatal intradermal vaccination using the same method $^{3}$ showed a $97 \cdot 3 \%$ tuberculin positive rate and $24 / 846(2 \cdot 84 \%)$ abscesses. Analysis by $\chi^{2}$ shows that the percutaneous BCG method produces a significantly higher tuberculin negative rate at 6-9 weeks compared with the intradermal method $\left(15 \cdot 8 \%\right.$ v $2 \cdot 7 \% ; \chi^{2} 69 \cdot 1 ; 0.0001>$ p) but that the abscess rate after vaccination was significantly lower $\left(0 \cdot 24 \% v 2 \cdot 84 \% ; \chi^{2} 7 \cdot 82\right.$; $0.01>p>0.001$ ).

\section{Discussion}

The lower tuberculin reactivity rate after percutaneous BCG could be due to the different technique or to type of vaccine, the latter being unlikely because of the quality control testing of such vaccines. The lower tuberculin positive response rate does not automatically equate with lower protective efficacy. A large number of factors determine whether tuberculin sensitivity develops after BCG vaccination and its initial strength. ${ }^{7}$ Significant protection can still be derived from BCG vaccination even with a negative tuberculin response. ${ }^{8}$ It may also be that the tuberculin reactivity rate could rise further with time. Cundall et al reported 68\% Heaf conversion rate four months after neonatal BCG by a multiple puncture technique, ${ }^{9}$ which rose to $88 \%$ at 1 year. ${ }^{5}$

The percutaneous method was found to be much more 'user friendly' than the intradermal method for newborn babies, particularly when carried out by junior staff, and this is borne out by the much lower abscess rate. The percutaneous BCG method as described is easy to use in practice and gives an acceptably high tuberculin conversion rate.

1 Subcommittee of the Joint Tuberculosis Committee of the British Thoracic Society. Control and prevention of tuberculosis in Britain: an updated code of practice. BMF 1990; 300: 995-9.

2 Packe GE, Innes JA. Duration of protective against tuberculosis conferred by BCG vaccination in infancy. Arch Dis Child conferred by BCG

3 Ormerod LP, Garnett JM. Tuberculin response after neonatal BCG vaccination. Arch $D$ is Child 1988; 63: 1491-2.

4 Ormerod LP, Garnett JM. Tuberculin reactivity 4 years after neonatal BCG vaccination. Arch Dis Child 1992; 67: 530-1.

5 Teale CE, Cundall DB, Pearson SB. Heaf status after infant BCG immunization. Tubercle and Lung Disease 1992; 73: 210-2.

6 Department of Health. Immunization against infectious disease. London: HMSO, 1992: 76-94.

7 Snider DE. Bacille Calmette-Guerin vaccinations and tuberculin skin tests. $\mathcal{F} A M A 1985 ; 253: 3438-9$.

8 D'Arcy Hart P, Sutherland I, Thomas J. The immunity conferred by effective BCG and vole bacillus vaccines in relation to individual variations in induced tuberculin sensitivity and to technical variations in the vaccines. Tubercle 1967; 48: 201-10.

9 Cundall DB, Ashelford DJ, Pearson SB. BCG immunisation of infants by percutaneous multiple puncture. $B M \mathcal{F} 1988 ; 297$ : 1173-4. 